Hum. Genet. 36, 25-33 (1977)

\title{
Partial Trisomy of the Long Arm of Human Chromosome 1 as Demonstrated by in situ Hybridization with 5S Ribosomal RNA
}

\author{
Dale M.Steffensen ${ }^{1}$, Ernest H. Y. Chu ${ }^{2 *}$, David P. Speert ${ }^{3}$, Patrick M. Wall ${ }^{3}$, \\ Karen Meilinger ${ }^{2}$, and Robert P. Kelch ${ }^{3}$ \\ ${ }^{1}$ Department of Genetics and Development, University of Illinois, Urbana, Illinois 61 801, USA \\ ${ }^{2}$ Department of Human Genetics and \\ ${ }^{3}$ Department of Pediatrics and Communicable Diseases, The University of Michigan Medical \\ School, Ann Arbor, Michigan 48 109, USA
}

\begin{abstract}
Summary. In a newborn boy with multiple malformations, a tandem duplication was detected at the distal end of the long arm of one human chromosome 1 . The Giemsa bands, 1q31 to 1q43-44, were repeated serially. Since 5S rRNA genes are located at 1q42 - 43, in situ hybridization of ${ }^{125}$ I 5S rRNA with fixed chromosome preparations was used to confirm the chromosomal duplication. The infant exhibited numerous developmental and clinical abnormalities as might be expected with an abnormality of chromosome structure relating to a ribosome component.
\end{abstract}

\section{Introduction}

A newborn White male exhibited abnormal physical features including small pointed mandible, small eyes with corneal opacities, small and low-set ears, short sternum, and long fingers and toes (Fig. 1). Progressive respiratory and hepatic insufficiencies resulted in death at six weeks of age.

Chromosome analysis of cultured leukocytes revealed extra chromosomal material at the distal end of the long arm of one chromosome 1. This chromosome finding was of considerable interest because clinical syndromes associated with structural abnormalities of human A group chromosomes are rare. Furthermore, the abnormal chromosome 1 seemed to possess a duplicated segment containing the 5S ribosomal RNA genes (Steffensen et al., 1974, 1975; Atwood et al., 1975). One 5S rRNA molecule is present per 60S ribosomal RNA particle and 5S rRNA is required for normal ribosome function during protein synthesis. We report this case in detail to document physical and clinical abnormalities associated with trisomy of the distal portion of the long arm of chromosome 1.

* To whom offprint requests should be sent 

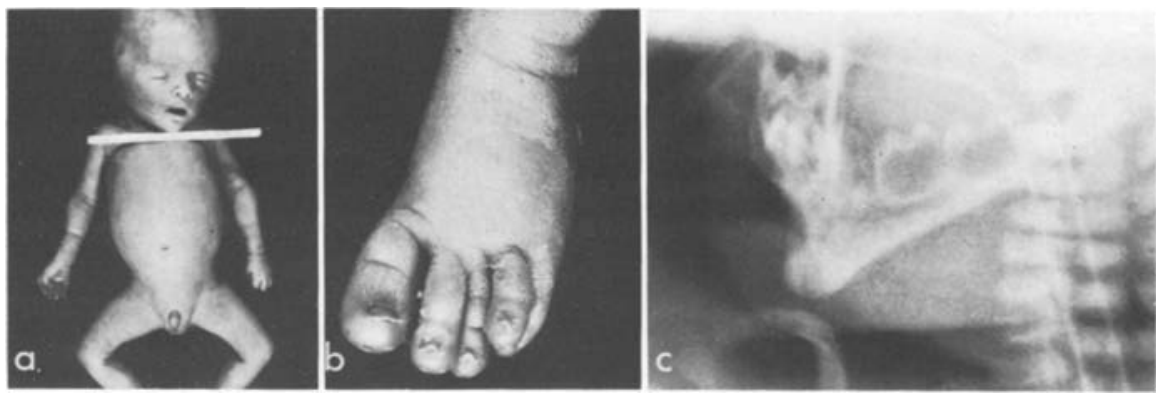

Fig. 1. a Appearance of propositus at necropsy. b Close-up view of left foot at necropsy. c Lateral radiograph of lower jaw and cervical spine

\section{Case Report}

$\mathrm{KBH}$, a five-day-old White male, was transferred to the University of Michigan Medical Center for treatment of progressive respiratory insufficiency. The patient weighed $2320 \mathrm{~g}$ after a 35 -week pregnancy in a 24-year-old primigravida. There is no history of infertility or exposure to radiation or drugs in parents. Because of low maternal estriol excretion, Class I diabetes, and failure of progression in labor, a Caesarean section was performed under spinal anesthesia. The lecithin:sphingomyelin ratio of amniotic fluid was 3:1 prior to delivery. Apgar scores were 7 and 7 at 1 and 5 minutes respectively. Initial hypoglycemia was treated with intravenous dextrose. At two days of age, the baby had two episodes of apnea and bradycardia and regurgitated feedings. Samples of peripheral blood, cerebrospinal fluid and urine were obtained, after which ampicillin and kanamycin treatment was begun. On the fifth day of life, the baby developed progressive respiratory insufficiency. A chest x-ray showed bilateral pulmonary infiltrates, and the baby was transferred to the Holden Newborn Intensive Care Unit.

Physical examination on admission revealed a head circumference of $34 \mathrm{~cm}$, length $46 \mathrm{~cm}$, weight $2.3 \mathrm{~kg}$ and a heart rate $120-140$ beats per minute and marked tachypnea was present. Examination of the head revealed a large anterior fontanelle, a widely patent metopic suture, frontal bossing, mid-facial hypoplasia and a triangular-shaped face with a pointed jaw. The eyes were small with an antimongoloid slant and corneal opacities. The ears were small, low-set and posteriorly rotated. The nose had a low, flat bridge, and there was microstomia. He had redundant nuchal skin folds and widely spaced nipples. Breath sounds were decreased bilaterally with dry inspiratory rales, but no retractions or nasal flaring were noted. The penis was small with a chordee, and the right testis was not palpable. There was an apparent pseudoarthrosis of the right forearm. The toes and fingers were long and slender with dysplastic, concave nails (Fig. 1). Moro and suck reflexes were good; the baby moved all extremities well, had good muscle tone and cried actively, but did not respond to pain.

The baby was treated with ampicillin and gentamicin for pneumonitis. Pulmonary infiltrates failed to clear after ten days of antibotic therapy. Viral and bacterial cultures of cerebrospinal fluid, blood, urine and nasopharynx were all negative. Total serum IgM was $7 \mathrm{mg} \%$. The baby was unable to tolerate tube feedings because of gastric retention. A heart murmur was heard initially and believed to be secondary to a patent ductus arteriosus. An EKG was normal for age, and no treatment was instituted. There was mild but progressive hepatic insufficiency as evidenced by an increase in direct bilirubin from $0.6 \mathrm{mg} \%$ at 5 days to $4.2 \mathrm{mg} \%$ at one month; the level of serum glutamate oxaloacetate transaminase rose from 65 to 87 international units (IU) and that of alkaline phosphatase from 193 to 309 IU. In addition to the pulmonary infiltrates, reontgenograms on admission demonstrated soft tissue narrowing over the distal right radius with no underlying bone abnormality, bilaterally thin ribs (eleven on each side), and a small pointed mandible (Fig. 1). An EEG was within normal limits for age. Direct Coomb's, urinary ferric chloride, and urinary and serum amino acid screening tests gave normal results. Serum alpha-1 antitrypsin was $370 \mathrm{mg} \%$ (normal $163-245$ ). 
The patient's condition deteriorated slowly, and he required ventilatory support and continuous intravenous hydration. Hyperalimentation could not be instituted because of hepatic insufficiency. At 6 weeks of age he died.

Necropsy revealed passive congestion of the kidneys, liver, spleen and lungs. There was extramedullary hematopoiesis in the liver, with evidence of resolving hepatitis. The adrenal glands showed evidence of recent hemorrhage and nodular cortical hyperplasia. There was a $10 \mathrm{ml}$ serosanguinous pericardial effusion, a patent ductus arteriosus, a patent foramen ovale and the left carotid artery arose from the innominate artery. Focal stenosis of the common bile duct was noted, one cm proximal to the ampulla.

\section{Materials and Methods}

The standard method for slide preparation of mitotic chromosomes from cultured leukocytes was employed. The chromosomes were stained for Giemsa bands according to the method of Sun et al. (1974).

The 5S rRNA from HeLa cells was iodinated and given to us by Drs. Paul Szabo and Wolf Prensky. The method of iodination with ${ }^{125}$ (Prensky et al., 1973) has been described in detail recently by Prensky (1976). A third chromatographic purification, RPC-5 reverse phase (Pearson et al., 1971), was introduced to remove various impurities found in the commercial ${ }^{125} \mathrm{I}$ samples and traces of RNA species other than $5 \mathrm{~S}$ rRNA. The RPC-5 column was $0.1 \mathrm{~cm}$ wide by $30 \mathrm{~cm}$ long with a total volume of about $0.25 \mathrm{ml}$. The $5 \mathrm{~S}$ rRNA was eluted from the column under pressure with a 0.4 to $1.0 \mathrm{M} \mathrm{KCl}$ gradient. The purified ${ }^{125}$ IS rRNA had a specific activity of $1.1 \times 10^{8} \mathrm{dpm} / \mu \mathrm{g}$, and was used at $0.1 \mu \mathrm{g} / \mathrm{ml}$ in $50 \%$ formamide in $2 \times \mathrm{SSC}$ (SSC is $0.1 \mathrm{M} \mathrm{NaCl}, 0.015 \mathrm{M}$ sodium citrate at $\mathrm{pH} 6.4-6.8$ ). Before in situ hybridization the slide preparation was stored dry at $-20^{\circ} \mathrm{C}$. The methods for in situ hybridization have been discussed in detail (Steffensen, in press).

\section{Results}

Chromosome analysis revealed a $46 \mathrm{XY} \mathrm{1q+} \mathrm{karyotype.} \mathrm{Some} \mathrm{of} \mathrm{the} \mathrm{terminal}$ bands on the long arm of one chromosome 1 appeared to be duplicated (Fig. 2). The karyotypes of both parents were normal.

To verify the putative duplication, chromosome preparations from the same leukocyte culture were processed by the in situ RNA:DNA hybridization method using ${ }^{125}$ I labelled 5S rRNA with $50 \%$ formamide in $2 \times$ SSC. Denaturation of chromosomal DNA in situ with $0.2 \mathrm{~N} \mathrm{HCl}$ or $70 \%$ formamide did not seriously alter the appearance of chromosomes; both the normal and aberrant chromosome 1 were recognized easily. After hybridization overnight at $40^{\circ} \mathrm{C}$ the slides were covered with nuclear emulsion and the autoradiographs were exposed for one to two months. The first experiment gave autoradiographs that were slightly underexposed for illustration purposes. The autoradiographs were ideal for qualitative and quantitative analysis of the normal and duplicated chromosomes. A second experiment was performed with a samples of very high specific activity ${ }^{125}$ I $5 \mathrm{~S}$ rRNA, and the autoradiographs were overexposed. The data obtained from this experiment also indicated duplication of the 5S rRNA genes on the 1q+ chromosomes. These slides were not analyzed further because of the excessive number of silver grains.

In Figure 3 six sets of chromosome 1 pairs are shown. With the frequency of silver grains attained the 5S rRNA gene sites did not always exhibit label, as 


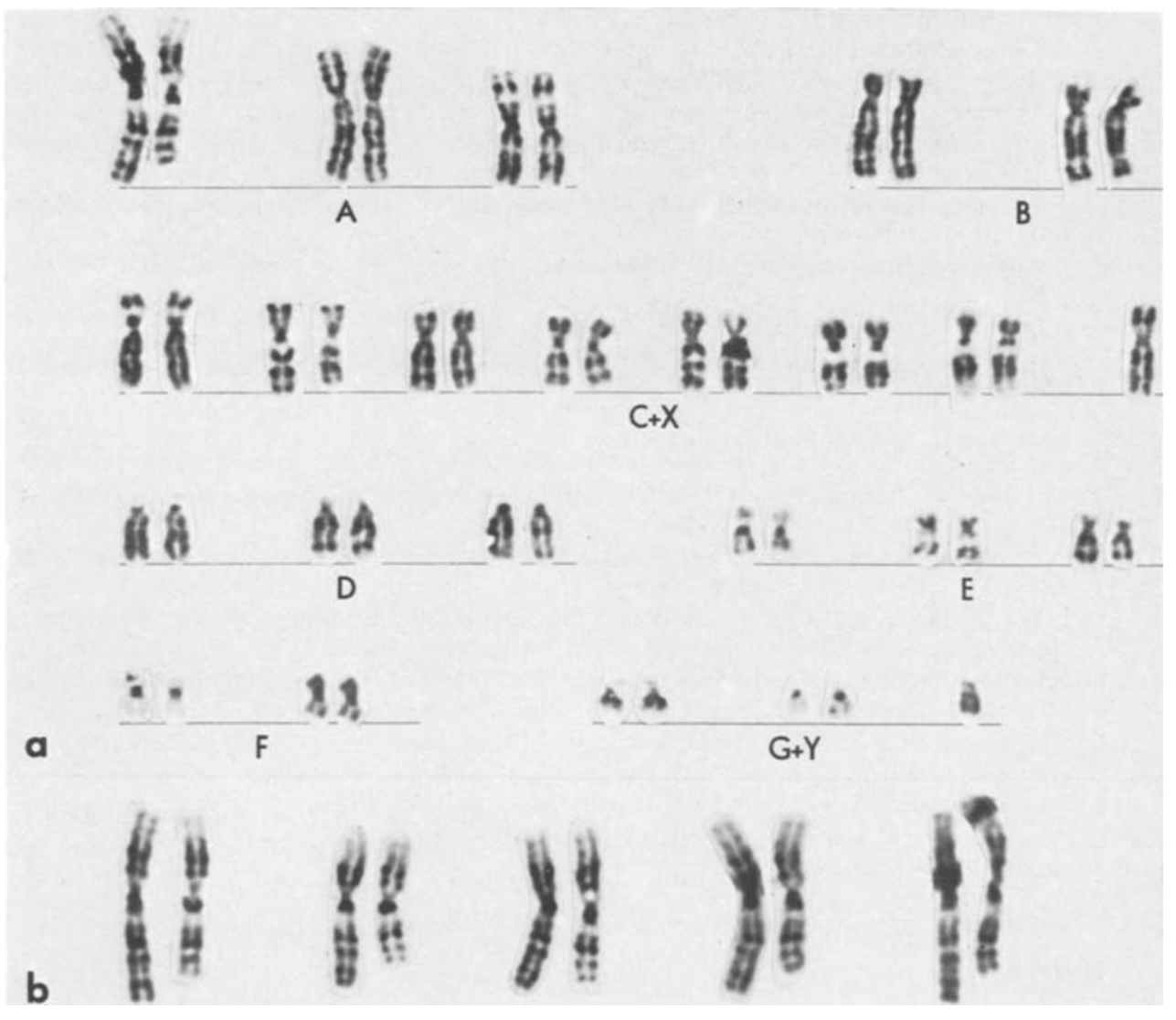

Fig. 2. a The karyotype of the propositus indicating extra chromosomal material at the distal end of the long arm of one chromosome 1. b Five additional sets of chromosome 1 pairs from different cells

expected by a Poisson distribution. On the normal chromosome 1 one site was labeled, as usual, at 1q42-43, while the duplicated chromosome had two labeled sites, one at the distal end of the chromosome at 1q42-43 and another more proximal corresponding to the expected $G$ bands patterns (Fig. 2) with a duplicated $1 \mathrm{q} 42-43$ region.

Table 1 presents the results of analysis of 112 metaphase figures from autoradiographs of the first experiment. These autoradiographs were especially free of background radioactivity because the ${ }^{125}$ I labeled 5S rRNA had been purified after iodination. The distribution of the radioactivity from the $5 \mathrm{~S}$ RNA:DNA hybrids was scored in terms of the number of silver grains appearing near the end of the long arms of both the normal and duplicated chromosomes 1 . The duplicated region had more than twice the number of silver grains of the normal chromosome 1 site at 1q42-43. Table 1 also indicates that $90 \%$ of the $5 \mathrm{~S}$ rRNA radioactivity was noted in chromosome 1. 


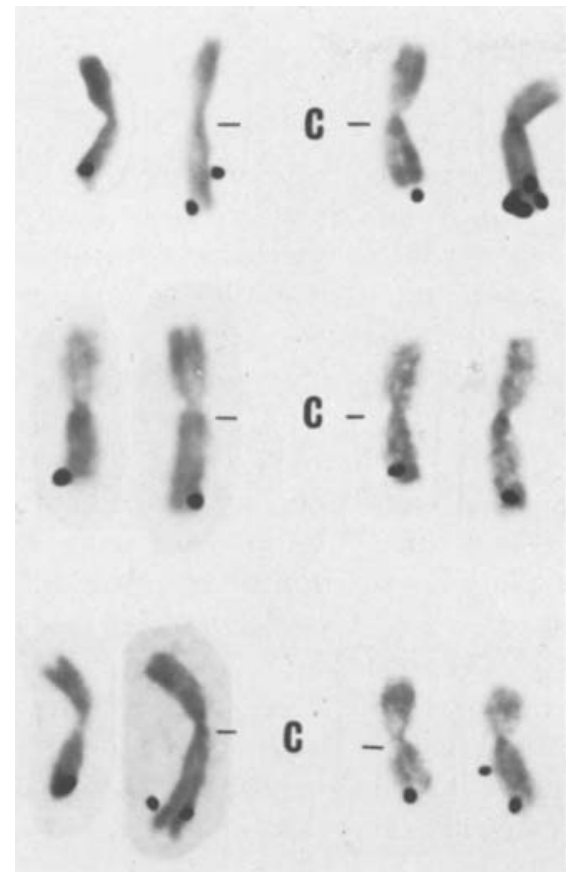

Fig. 3. Autoradiographs of in situ annealing of 125 I SS rRNA to human chromosome 1. Six chromosome pairs are shown with the normal chromosome 1 on the left and the $1 \mathrm{q}+$ chromosome on the right. $\mathrm{C}$ indicates the large $\mathrm{C}$ band at $1 \mathrm{q} 12$, commonly referred to as $\mathrm{lqh}$. The distribution of the radioactivity indicates that the $1 \mathrm{q}+$ chromosome possesses two 5S rRNA gene loci as diagrammed in Figure 4

Table 1. Autoradiographic analysis of cells carrying a duplication of the 5S rRNA genes on chromosome 1 as detected by in situ hybridization with ${ }^{125}$ I 5 S rRNA

\begin{tabular}{|c|c|c|c|c|c|c|}
\hline & & \multicolumn{2}{|c|}{ Number of silver grains } & \multirow{2}{*}{$\begin{array}{l}\text { Total } \\
\text { grains }\end{array}$} & \multirow{2}{*}{$\begin{array}{l}\text { Label per } \\
\text { chromosome } \\
\text { or site }\end{array}$} & \multirow{2}{*}{$\begin{array}{l}\text { Percent } 5 S \text { genes } \\
\text { per haploid site } \\
\text { or chromosome* }\end{array}$} \\
\hline & & slide 1 & slide 2 & & & \\
\hline \multirow{2}{*}{$\begin{array}{l}\text { Duplicated } \\
\text { chromosome } 1\end{array}$} & $\left\{\begin{array}{l}\text { Proximal } \\
5 \text { S site }\end{array}\right.$ & 28 & 88 & 116 & $116)$ & \multirow{3}{*}{$\begin{array}{l}90.1 \\
\text { (average 101.3 } \\
\text { silver grains) }\end{array}$} \\
\hline & 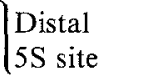 & 18 & 80 & 98 & 98 & \\
\hline \multicolumn{2}{|c|}{$\begin{array}{l}\text { Normal chromosome } 1 \\
5 \mathrm{~S} \text { site (1q 42-43) }\end{array}$} & 16 & 74 & 90 & $90 丁$ & \\
\hline \multicolumn{2}{|c|}{ A group $(-1)$} & 0 & 6 & 6 & 1.5 & 1.3 \\
\hline \multicolumn{2}{|l|}{ B group } & 3 & 12 & 15 & 2.5 & 2.2 \\
\hline \multicolumn{2}{|l|}{ C group $(+X)$} & 10 & 25 & 35 & 2.7 & 2.4 \\
\hline \multicolumn{2}{|l|}{ D group } & 1 & 15 & 16 & 2.7 & 2.4 \\
\hline \multicolumn{2}{|l|}{ E group } & 2 & 5 & 7 & 1.2 & 1.0 \\
\hline \multicolumn{2}{|l|}{ F group } & 1 & 0 & 1 & 0.25 & 0.2 \\
\hline \multicolumn{2}{|l|}{$\mathrm{G}$ group $(+\mathrm{Y})$} & 1 & 0 & 1 & 0.2 & 0.2 \\
\hline \multicolumn{2}{|l|}{ Number of cells } & 31 & 81 & & & \\
\hline \multicolumn{2}{|c|}{ Total silver grains } & 80 & 305 & 385 & & \\
\hline
\end{tabular}

* The silver grains attributed to background have not been subtracted 


\section{Discussion}

Although the A group human chromosomes account for approximately $25 \%$ of the human genome, there is no constant clinical syndrome associated with structural chromosomal abnormalities of this group, as compared with other groups of human chromosomes. A number of structural variations and anomalies involving chromosome 1 have been reported (for references, see Borgaonkar, 1975). Among duplications of the long arm of chromosome $1(1 \mathrm{q}+)$, the $1 \mathrm{qh}+$ variant is the most common. Hecht et al. (1975) studied 551 phenotypically normal children and found this normal variant in a heterozygous condition in 41 (7.1\%). Hamerton et al. (1972) found a 0.4/1000 incidence among newborn children. The enlargement of chromosome 1 in these instances is due to an elongation of the heterochromatic (h) secondary constriction on the long arm near the centromere. The present case is an example of duplication of 1q31-44 region and is distinctly different from the $1 \mathrm{qh}+$ variants.

Sanger et al. (1974) described partial trisomy $\mathrm{lq}$ in three patients, whose unbalanced karyotypes were derived by segregation in translocation heterozygotes. All three had trisomy of the segment of 1q distal to band q32. There were several features in common among these patients including short stature, obesity, dolichocephaly with obvious narrowing of the craniofacial features, long nose, prominent premaxilla and short philtrum. The thumbs were broad in two patients, and duplicated in one. The authors suggested that these features, particularly the cranio-facial findings, were related to the trisomic state. With the exception of narrow facies, these cases did not appear to have the same morphological abnormalities as the propositus in this study. It should be pointed out, however, that even though all the 4 cases were duplications for the same chromosome 1 segment $(1 \mathrm{q} 32 \rightarrow$ ter $)$, other karyotypic differences do exist among them. Sanger's patients were partially deficient for chromosome 2 or $\mathrm{X}$, but there was probably little or no deficiency involved in the propositus. Further studies with additional cases are necessary before a more difinitive association can be established between physical abnormalities and partial trisomy for the distal end of the long arm of human chromosome 1.

Trisomy 1 or partial trisomy for the long arm of chromosome 1 has been reported in two patients with polycythemia and one with acute leukemia (Rowley, 1975), and in one with refractory dysplastic anemia considered to be most consistant with a diagnosis of erythremic myelosis (Warburton and Bluming, 1973). Two additional cases (Wurster-Hill et al., 1976) bring the number of hemopathic cases to six involving extra material from chromosome 1. Particular susceptibility of chromosome 1 to rearrangement (beyond that expected due to its length) in cells of human ovarian tumors has also been described (Tiepolo and Zuffardi, 1973), but the rearrangements were variable.

Our data from molecular in situ hybridization studies support the morphological evidence that the abnormal chromosome 1 had a tandemly duplicated segment at the distal end of the long arm. The karyotype of the propositus can therefore be designated as $46, \mathrm{XY}$ dup (1)q $32 \rightarrow \mathrm{q}$ ter.

We can only speculate about the possible mechanisms(s) of the origin of this chromosome abnormality. Since both parents of the propositus were normal, it 


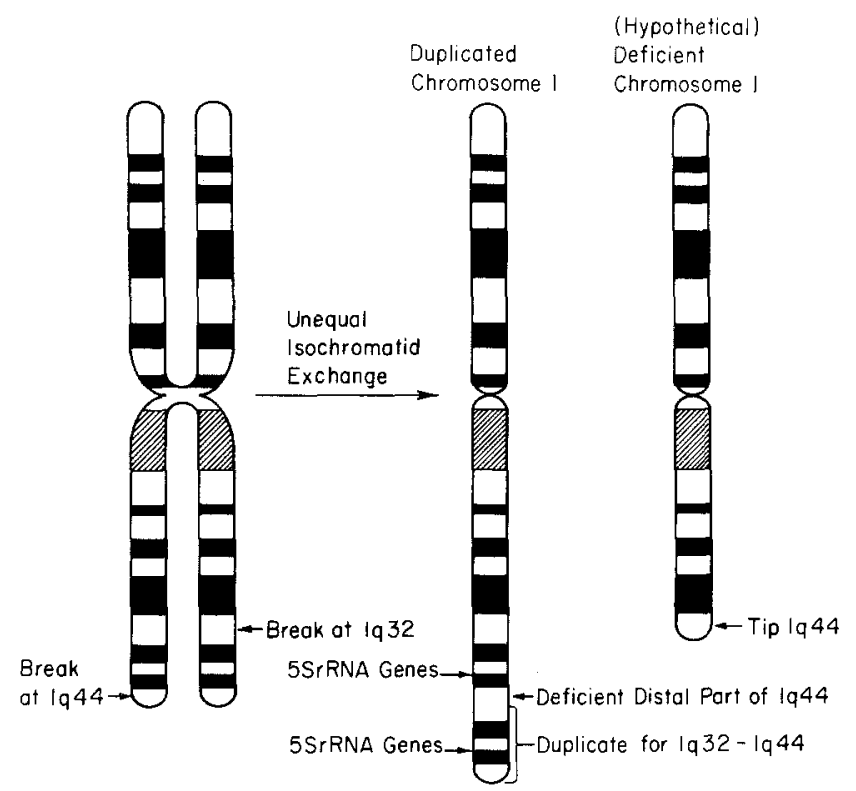

Fig. 4. Schematic drawing of human chromosome 1 with Giemsa banding pattern. The diagram also shows a hypothetical mechanism of sister chromatid unequal exchange, leading to the formation of a duplicated and a deficient chromosome 1

follows that the duplicated chromosome probably arose in either parent before fertilization. The simplest explanation of this abnormality is unequal sister chromatid exchange during meiosis or mitosis, as diagrammed in Figure 4. With two chromatid breaks followed by unequal isochromatid rejoining, a duplicated chromosome 1 and a deficient chromosome 1 would result. Similarly, unequal exchange or crossing over during meiosis or a reciprocal translocation between the long arms of the two chromosome 1 homologues could give rise to the same result. When the abnormal gamete carrying the duplicated chromosome was fertilized by a normal gamete, the resultant zygote was the duplication heterozygote.

This duplicated segment is the location of genes coding for several important enzyme functions, as indicated in a recent map (Hamerton and Cook, 1975). It seems entirely possible that the propositus had problems with an excess of $5 \mathrm{~S}$ rRNA genes, thus overloading the assembly of the $60 \mathrm{~S}$ particle of the ribosome. It is also possible that a gene coding for an enzyme in 3 doses, such as peptidase-C, fumarate hydratase, or guanylate kinase-1, could have had certain deleterious effects. Ohno (1970) has discussed a number of possible genetic consequences of chromosome regional duplications. One shortcoming of tandem duplication is the disruption of the established gene dosage ratio between functionally related genes. Another difficulty is that tandem duplication may duplicate the structural cistron without duplicating the regulatory gene which controls its activity. Unfortunately, no further research can be done with this case since the infant died and tissues could not be taken for cell culture. 
The duplicated chromosome diagrammed in Figure 4 should have just one dose of $1 \mathrm{q} 44$ at the tip of chromosome 1. This segment is probably the telomere and consists of repeated DNA sequences (Saunders et al., 1972). The section 1q32 has been reported as a breakpoint for several translocation and deficiencies (cf. Borgaonkar, 1975), and may be a breakage "hot spot".

In Table 1 evidence was presented which indicated that $90 \%$ of the $5 \mathrm{~S}$ rRNA radioactivity is on chromosome 1 . The remaining $10 \%$ of the radioactivity could be ascribed to noise from background, possibly due to contaminating RNA which was not $5 \mathrm{~S}$, and iodine labeled impurities which was not RNA, such as labeled proteins. Further RNA: DNA hybridization should be done on filters or with DNA in solution to test our finding critically. Highly purified 5S rRNA will be necessary to rule out contamination from other molecular species. We are tempted to believe that all of the 5S rRNA genes are on chromosome 1 because of these very clean autoradiographs. Highly purified ${ }^{125}$ I $5 \mathrm{~S}$ rRNA will be required to repeat the work of Aloni et al. (1971) and to calculate the actual number of $5 \mathrm{~S}$ rRNA genes in the human genome. Given that chromosome 1 has all or nearly all of the 5S rRNA genes, we can understand why products of conception with rearrangements of this chromosome are not commonly recovered and why it has been so conservative in normal evolution according to Pearson (1973) and others.

Acknowledgement. This research was supported by a U.S. Public Health Service grant GM 21 123-02 to D.M.S. and by grant (C-111) from the National Foundation to the Birth Defects Diagnostic Laboratory, operated jointly by the Departments of Human Genetics and Pediatrics, University of Michigan.

\section{References}

Aloni, Y., Halten, L. E., Attardi, G.: Studies on the fractionated HeLa cell metaphase chromosomes. II. Chromosomal distribution of sites for transfer RNA and 5S RNA. J. Mol. Biol. 56, 555-563 (1971)

Atwood, K. C., Yu, M. T., Johnson, L. D., Henderson, A. S.: The site of 5S RNA genes in human chromosome 1. Cytogenet. Cell Genet. 15, 50-54 (1975)

Borgaonkar, D. S.: Chromosomal variation in man. Baltimore: Johns Hopkins University Press 1975

Hamerton, J. L., Cook, P. J. L.: Report of the committee on the genetic constitution of chromosomes 1 and 2. Cytogenet. Cell Genet. 14, 173-182 (1975)

Hamerton, J. L., Ray, M., Abbott, J., Williamson, C., Ducasse, G. C.: Chromosome studies in a neonatal population. Canad. Med. Assoc. J. 106, 776-779 (1972)

Hecht, F.: Disease state exhibiting visible chromosomal abnormalities. In: Endocrine and genetic diseases of childhood and adolescence, L. L. Gardner, ed., 2nd edition, pp. 675-701. Philadelphia: Saunders 1975

Ohno, S.: Evolution by gene duplication. Berlin/Heidelberg/New York: Springer-Verlag 1970

Pearson, P. L.: The uniqueness of the human karyotype. In: Chromosome identification: technique and applications in biology and medicine, Nobel Symposium, Vol. 23, T. Caspersson and L. Zech, eds., pp. 145-151. New York: Academic Press 1973

Pearson, R. L., Weiss, J. F., Kelmers, A. D.: Improved separation of transfer RNA's on polychlorotrifluoroethylene-supported reversed-phase chromatography columns. Biochem. Biophys. Acta 228, 770-774 (1971)

Prensky, W.: The radioiodination of RNA and DNA to high specific activities. In: Methods in Cell Biology, Vol. 13, D. M. Prescott, ed., pp. 121-152. New York: Academic Press 1976 
Prensky, W., Steffensen, D. M., Hughes, W. L.: The use of iodinated RNA for gene localization. Proc. Nat1. Acad. Sci. USA 70, 1860-1864 (1973)

Rowley, J. D.: Abnormalities of chromosome 1 in myeloproliferative disorders. Cancer 36, $1748-1757$ (1975)

Sanger, R., Alfi, O., Donnell, G.: Partial trisomy 1q in 3 patients. Amer. J. Human Genet. 26, 75 A (1974)

Saunders, G. F., Shirakawa, S., Saunders, P. P., Arrighi, F. E., Hsu, T. C.: Populations of repeated DNA sequences in the human genome. J. Mol. Biol. 63, 323-334 (1972)

Steffensen, D. M.: Human gene localization by RNA: DNA hybridization in situ. In: Chromosomes in biology and medicine, J. J. Yunis, ed., volume 1. New York: Academic Press (in press)

Steffensen, D. M., Duffey, P., Prensky, W.: Localisation of 5S ribosomal RNA genes on human chromosome 1. Nature 252, 741-743 (1974)

Steffensen, D. M., Prensky, W., Mutton, D., Hamerton, J. L.: Mapping the human 5S RNA genes on chromosome 1 using translocations. Cytogenet. Cell Genet. 14, 434-438 (1975)

Sun, N. C., Chu, E. H. Y., Chang, C. C.: Staining method for the banding patterns of human mitotic chromosomes. Caryologia 27, 315-324 (1974)

Tiepolo, L., Zuffardi, O.: Identification of normal and abnormal chromosomes in tumor cells. Cytogenet. Cell Genet. 12, 8-16 (1973)

Warburton, D., Bluming, A.: A "Philadelphia-like" chromosome derived from the $Y$ in a patient with refractory dysplastic anemia. Blood 42, 799-804 (1973)

Wuster-Hill, D., Whang-Peng, J., McIntyre, O. R., Hsu, L. Y. F., Hirschhorn, K., Modan, B., Pisciotta, A. V., Pierre, R., Balcerzak, S. P., Weinfeld, A., Murphy, S.: Cytogenetic studies in polycythemia vera. Seminar Hematol. 13, 13-32 (1976) 